\title{
SNAP-27 Radioisotopic
}

Heat Source Summary Report

\author{
D. L. Prosser
}

AEC Research and Development Report

MOUND LABORATORY

operated by

MONSANTO RESEARCH CORPORATION a subsidiary of Monsanto Company

for the

U. S. ATOMIC ENERGY COMMISSION 


\section{DISCLAIMER}

This report was prepared as an account of work sponsored by an agency of the United States Government. Neither the United States Government nor any agency Thereof, nor any of their employees, makes any warranty, express or implied, or assumes any legal liability or responsibility for the accuracy, completeness, or usefulness of any information, apparatus, product, or process disclosed, or represents that its use would not infringe privately owned rights. Reference herein to any specific commercial product, process, or service by trade name, trademark, manufacturer, or otherwise does not necessarily constitute or imply its endorsement, recommendation, or favoring by the United States Government or any agency thereof. The views and opinions of authors expressed herein do not necessarily state or reflect those of the United States Government or any agency thereof. 


\section{DISCLAIMER}

Portions of this document may be illegible in electronic image products. Images are produced from the best available original document. 


\section{PRINTED IN THE UNITED STATES OF AMERICA}

Available from

Clearinghouse for Federal Scientific and Technical Information

National Bureau of Standards, U.S. Department of Commerce

Springfield, Virginia 22151

Price: Printed Copy $\$ 3.00$; Microfiche $\$ 0.65$

\section{LEGAL NOTICE}

This report was prepared as an account of Government sponsored work. Neither the United States, nor the Commission, nor any person acting on behalf of the Commission:

A. Makes any warranty or representation, expressed or implied, with respect to the accuracy, completeness, or usefulness of the information contained in this report, or that the use of any information, apparatus, method, or process disclosed in this report may not infringe privately owned rights: or

$B$. Assumes any liabilities with respect to the use of, or for damages resulting from the use of any information, apparatus, method, or process disclosed in this report.

As used in the above, "person acting on behalf of the Commission" includes any employee or contractor of the Commission, or employee of such contractor, to the extent that such employee or contractor of the Commission, or employee of such contractor prepares, disseminates, or provides access to, any information pursuant to his employment or contract with the Commission, or his employment with such contractor. 
MLM-1698

TID.4500

UC-23 Radioisotope and

Radiation Application

\title{
SNAP-27 Radioisotopic Heat Source Summary Report
}

\author{
D. L. Prosser
}

Issued: November 11, 1969

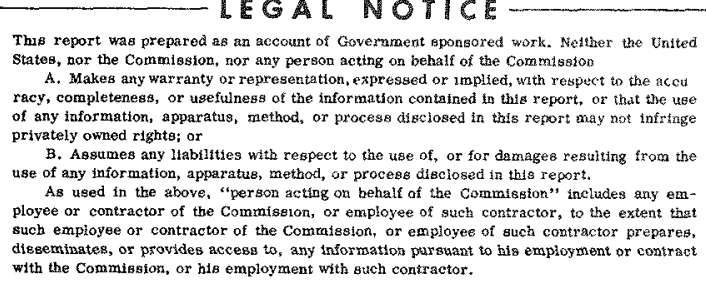

MONSANTO RESEARCH CORPORATION

A Subsidiary of Monsanto Company

MOUND LABORATORY

Miamisburg, Ohio operated for

UNITED STATES ATOMIC ENERGY COMMISSION

U.S. Government Contract No. AT-33-1-GEN-53 


\begin{abstract}
Six SNAP-27 thermoelectric generators were fabricated to provide electrical power for the Apollo Lunar Surface Experiments Package (ALSEP), a series of five experiments to be performed on the lunar surface after the SNAP-27 is transported there by the Apollo 12. Each heat source is fueled with $3735 \mathrm{~g}$ of plutonium-238 dioxide microspheres which will produce 1480 thermal watts of power. The SNAP-27 heat source capsule was subjected to a comprehensive series of mechanical and environmental tests to ensure the integrity of the system prior to flight authorization.
\end{abstract}


In the fall of 1965 Mound Laboratory entered discussions with the Missile and Space Division (MSD) of the Genera1 Electric Company concerning the fueling of radioactive heat sources which would power a SNAP-27 thermoelectric generator. The development of the generator and the heat source design were funded by the U. S. Atomic Energy Commission, Division of Space Nuclear Systems. The heat source, Figure 1, containing plutonium238 radioisotopic fue 1 , and the generator, would provide at least $63.5 \mathrm{~W}$ of conditioned electrical power at $16 \mathrm{Vdc}$ under lunar operating conditions for a minimum of one year after being stored for up to two years.

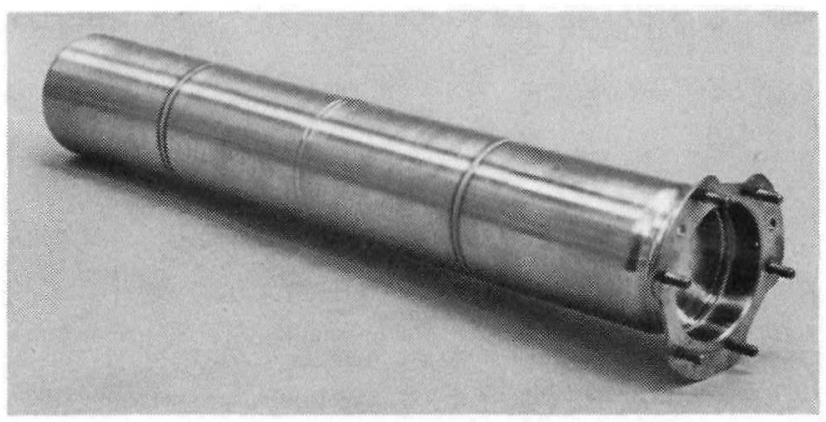

FIGURE 1 - The SNAP-27 radioisotopic heat source produces $1480 \mathrm{~W}$ of therma 1 power with plutonium-238 dioxide microsphere fuel. The source is about 16.5 in. $(41.9 \mathrm{~cm})$ overall length and $2.5 \mathrm{in.}$ $(6.4 \mathrm{~cm})$ in diameter.

The SNAP-27 system will provide power for the Apollo Lunar Surface Experiments Package (ALSEP) developed for the NASA Manned Spacecraft Center. The ALSEP is a package of instruments and supporting subsystems to be placed on the lunar surface by a crew member of the lunar module (LM) vehicle, and is designed to transmit lunar environmental information for at least one year after being placed on the moon's surface. The instrument package contains the following equipment:

1. Passive Seismic Experiment Package The instrument will measure lunar seismic activity. It will detect meteoroid impact and free oscillations in lunar rotation. It may also detect surface tilt tidal deformations resulting, in part, from periodic variations in the strength and direction of external gravitational fields acting on the moon.

2. Magnetometer Experiment The instrument will measure the magnetic flux of the moon and the possible effect on the moon of other magnetic fields in the solar system.

3. Solar Wind Experiment The instrument will measure the flux of ions on the moon which results from solar activity.

4. Supra Therma1 Ion Detector The instrument will measure protons and other ions in addition to those measured by the Solar Wind Detector.

5. Cold Cathode Gage Experiment The instrument is basically a gage for measuring small gas pressures. It will measure the low density of the lunar atmosphere.

The generator and package will be transported to the moon by the Apollo 12 vehicle.

Figure 2 portrays the scientific instruments in the lunar environment deployed around the generator shown in the foreground. Each heat source is fueled with about $3735 \mathrm{~g}$ of plutonium-238 dioxide microspheres to produce 1480 therma1 watts $[W(t)]$. The half-life of plutoni-

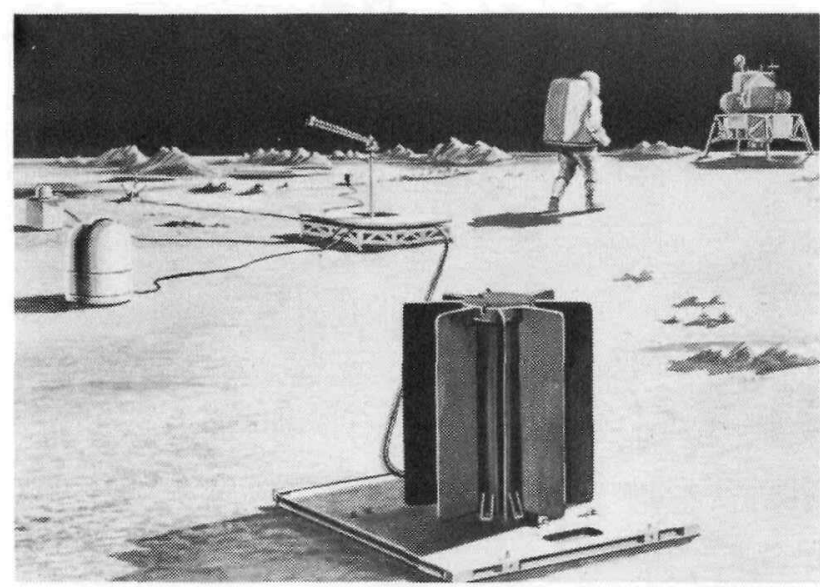

FIGURE 2 - The sketch illustrates the possible arrangement of the scientific instruments around the generator (foreground) and telemetry equipment (center) (Genera1 Electric MSD sketch). 
um-238 is 87.4 yr; it decays predominantly by alpha particle emission, with slight gamma and neutron radiation. The resultant power decay for the heat source will be less than $1 \%$ per year.

A total of six sources was fabricated for the SNAP-27 program. One source was used for test purposes and another as a standby unit for the remaining four designated for flight missions. The first of these four sources will be used for the Apollo 12 experiment.

A cutaway view of the heat source is shown in Figure 3. Table 1 lists some of the design parameters for the heat source. The capsule is of a dual design; each half contains an annular liner which holds the microsphere fuel. Helium gas generated by the decay of the fuel is accumulated in the inner volume of the liner to minimize pressure buildup in the capsule. Each half capsule was provided with a venting device to release the helium gas before the pressure reached a point which might jeopardize the integrity of the source. All seals were effected by either electron-beam or tungsten inert gas (TIG) welding methods.

The outer cladding components were fabricated from Haynes alloy No. 25. The alloy was used because of its good strength characteristics and its resistance to oxidation at the operating temperature of the heat source. For transportation to the moon the heat source was placed in a graphite LM fuel cask (GLFC) rather than in the generator (Figure 4). The GLFC provided protection for the heat source in the event of a possible launch pad explosion and also protected the source against the temperature and the heat of reentry in the case of an abort from space.

When the heat source reaches the moon it will be removed from the GLFC using a special handling tool (Figure 5) and placed in the generator. The tool is designed to be locked to a backplate attached to the flanged end of the heat

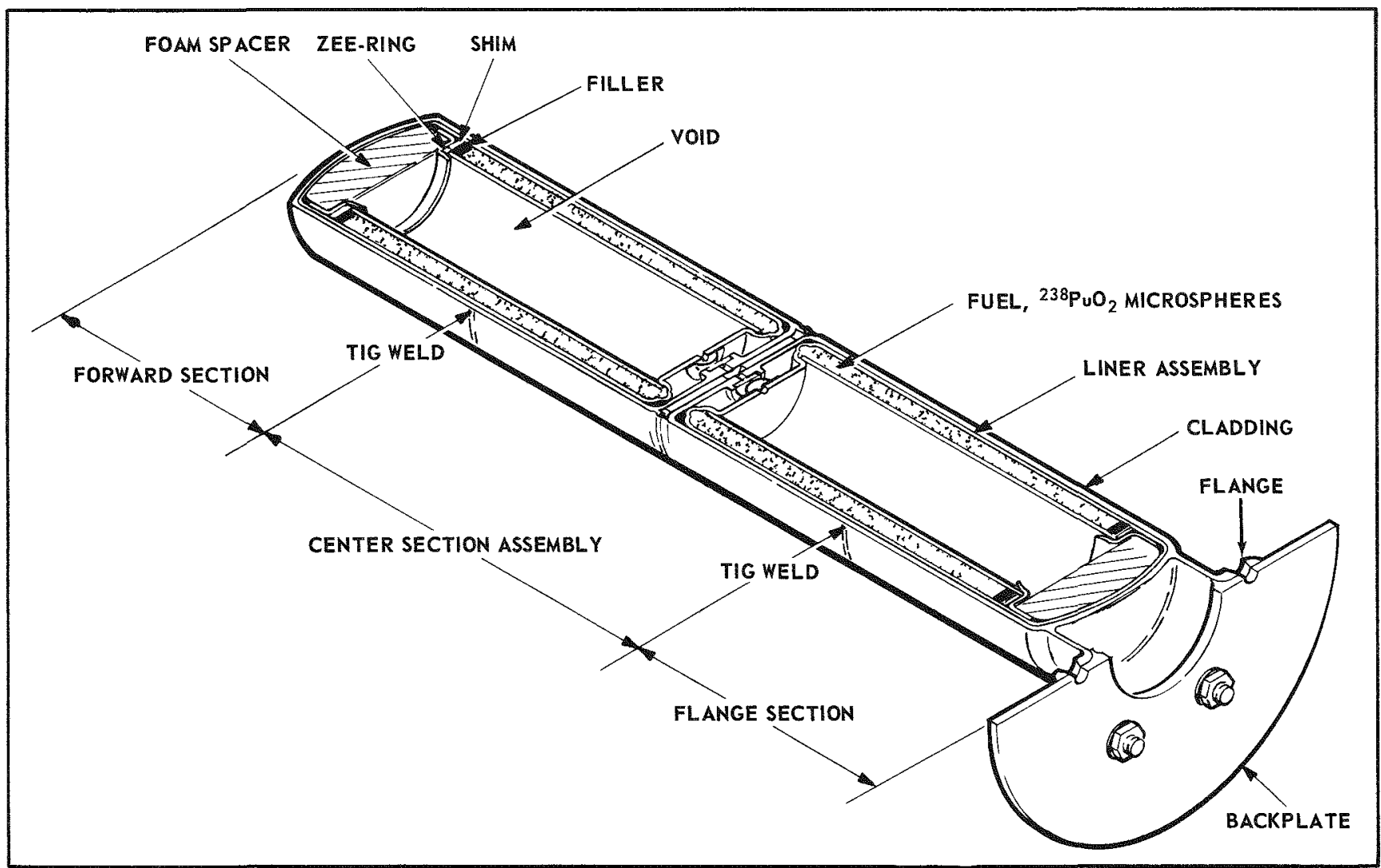

FIGURE 3 - Cutaway view of the SNAP-27 radioisotopic fuel capsule. 


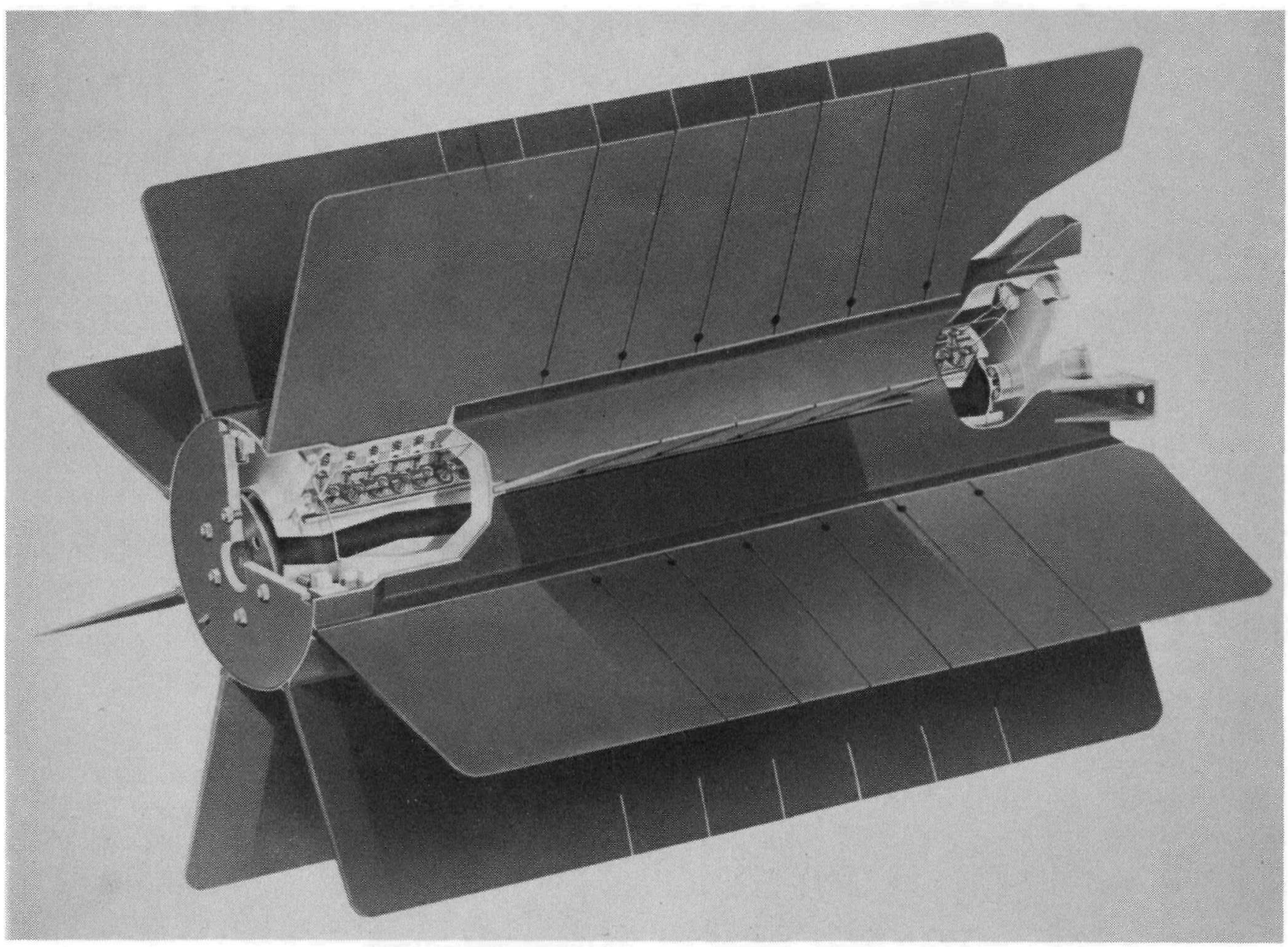

FIGURE 4 - SNAP-27 generator as semb1y.

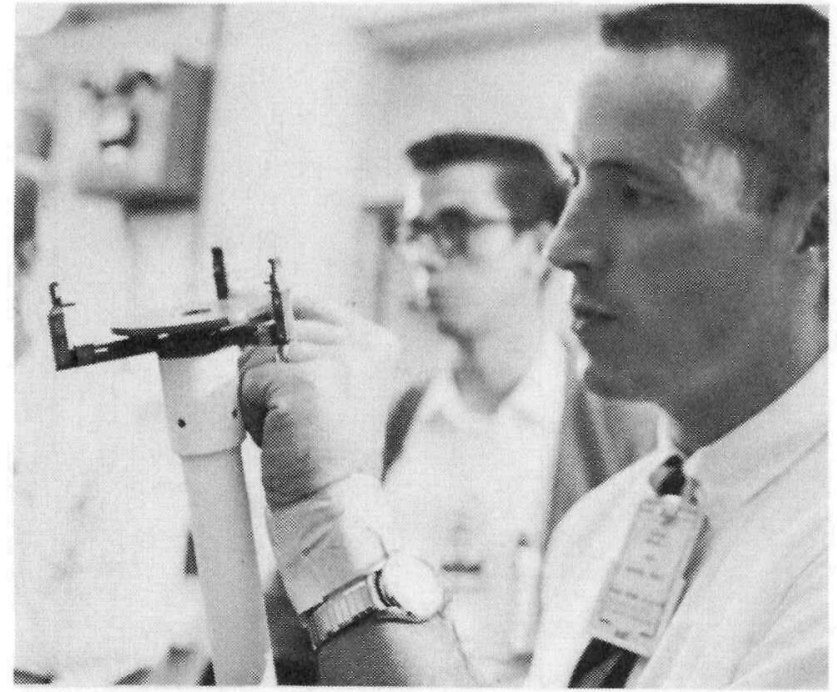

FIGURE 5 - This special handling tool is used to remove the SNAP-27 heat source from the GLFC and to place the source in the generator. source. The backplate is also used for locking the heat source into either the GLFC or generator.

The heat source was designed and the components provided by General Electric MSD. The fuel was fabricated and encapsulated in the heat source components by Mound Laboratory, Monsanto Research Corporation A11 capsules were completed in time to meet the Apollo timetable.

Because the heat source contained considerably more fuel than any source fabricated to date for aerospace applications, major importance was attached to the design of a heat protection system for the fuel capsule that would permit the capsule to survive an abort from earth orbit and land intact without dispersing plutonium within the biosphere. As one of the first major aerospace SNAP programs, the safety requirements 
SNAP-27 FUELED CAPSULE PROCESS FLOW DIAGRAM
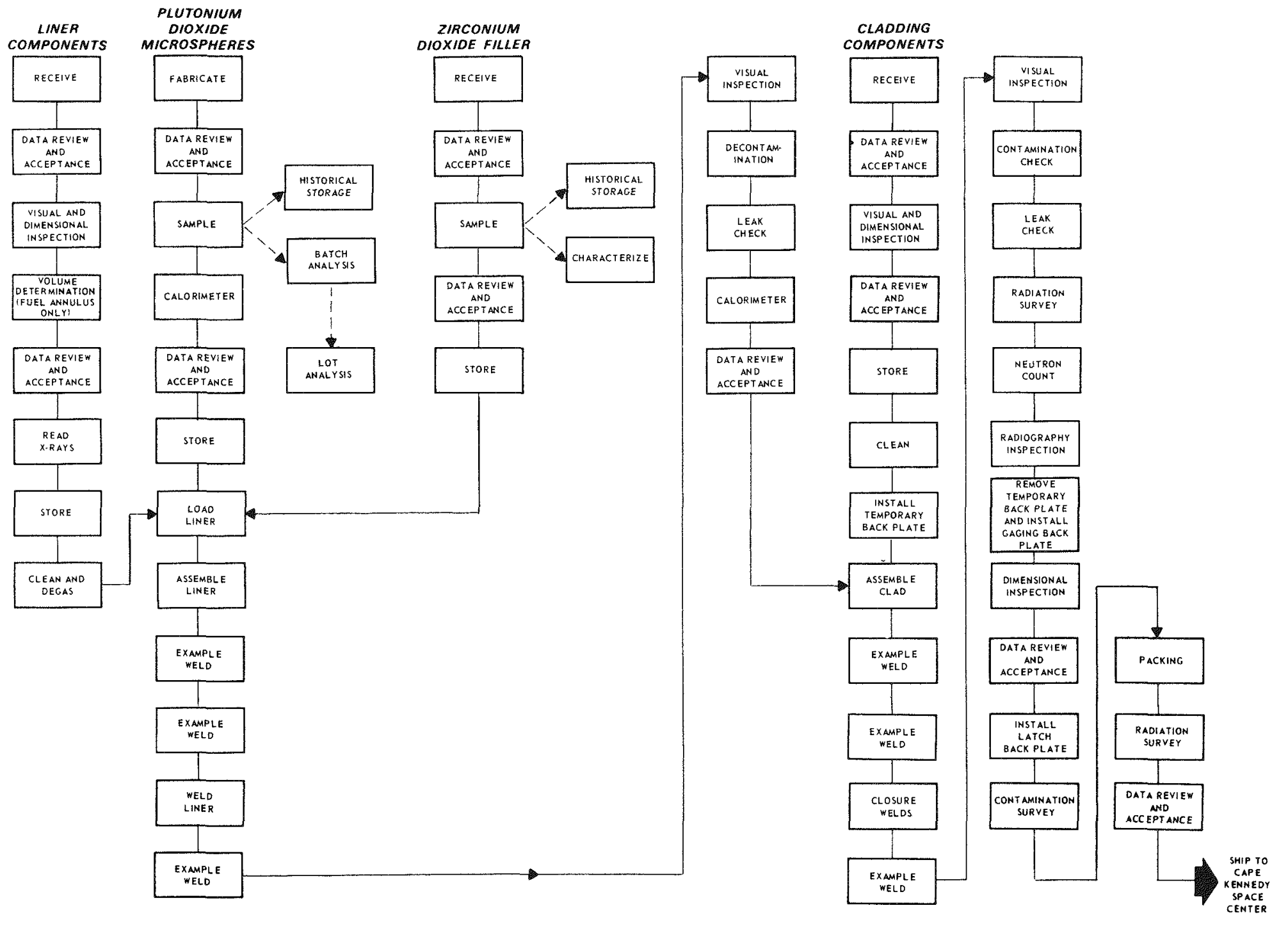
dictated intact reentry of the fuel capsule, and extensive developmental testing was conducted to establish the reliability of the reentry protection system. Rigorous inspection methods were instituted at Mound to guarantee fuel acceptability and to ensure the reliability of the many steps used to assemble the source.

Test capsules were subjected to a comprehensive series of mechanical tests and radiation measurements. The test capsules were exposed to all possible accidental conditions of impact, explosion, and heat that might be encountered before, during, or after the launch of the Saturn V space vehicle. The heat source integrity proved satisfactory after they were subjected to vibration and shock tests. In a report of February 28, 1969, the SNAP-27/ALSEP Interagency Safety Evaluation Panel reviewed the data obtained. Transportation, handling, launch, and post-launch hazards were all included. Following this study the sources were authorized for flight.

\section{Description of Heat Source}

Fue1: The thermal power requirement of $1480 \pm 30 \mathrm{~W}(\mathrm{t})$ was achieved using 50 to 250- $\mu$ m diam plutonium-238 dioxide microspheres prepared by fusion of oxide particles in a plasma torch. The actual fuel used for the flight hardware had the following characteristics:
Apparent density

Total impurities

Stoichiometry

Plutonium-238 content

Melting point

Fuel per capsule
- $10.08-10.54 \mathrm{~g} / \mathrm{cc}$

- 0.26-0.94 wt \%

$-2.00$

- 70.3-71.3 wt \%

- $2255 \pm 90^{\circ} \mathrm{C}$

- $\sim 3735 \mathrm{~g}$

$(\sim 44,500$
Encapsulation: The fuel was sealed in the annular cavity of each of the two liners required for the heat source. Both liners were subjected to rigorous inspection methods to ensure the integrity of the seal, and the thermal output of each liner was determined. The liners then were placed in the cladding components (Figure 3 ). One liner was inserted into the prewelded center section assembly, the forward section was placed over the exposed end of the liner, and the two cladding components joined by TIG welding. The second liner was enclosed in the other end of the center section assembly by using the flange section component. The welds were examined closely to guarantee their integrity. The cladding assembly provides a capsule free of surface radioactive contamination and acts as a strength member. The flow diagram, Figure 6, summarizes the fabrication procedure.

After all inspection operations were completed the heat sources were stored in the ground shipping cask (GSC) (Figure 7) until shipped to Cape Kennedy. The GSC was specifically designed to attenuate the neutron and gamma radiation emanating from the capsule to a level acceptable for handling. It also provided a system to adequately cool the capsule during storage or transportation. The GSC also protected the capsule against accidenta 1 handling and shipping hazards.

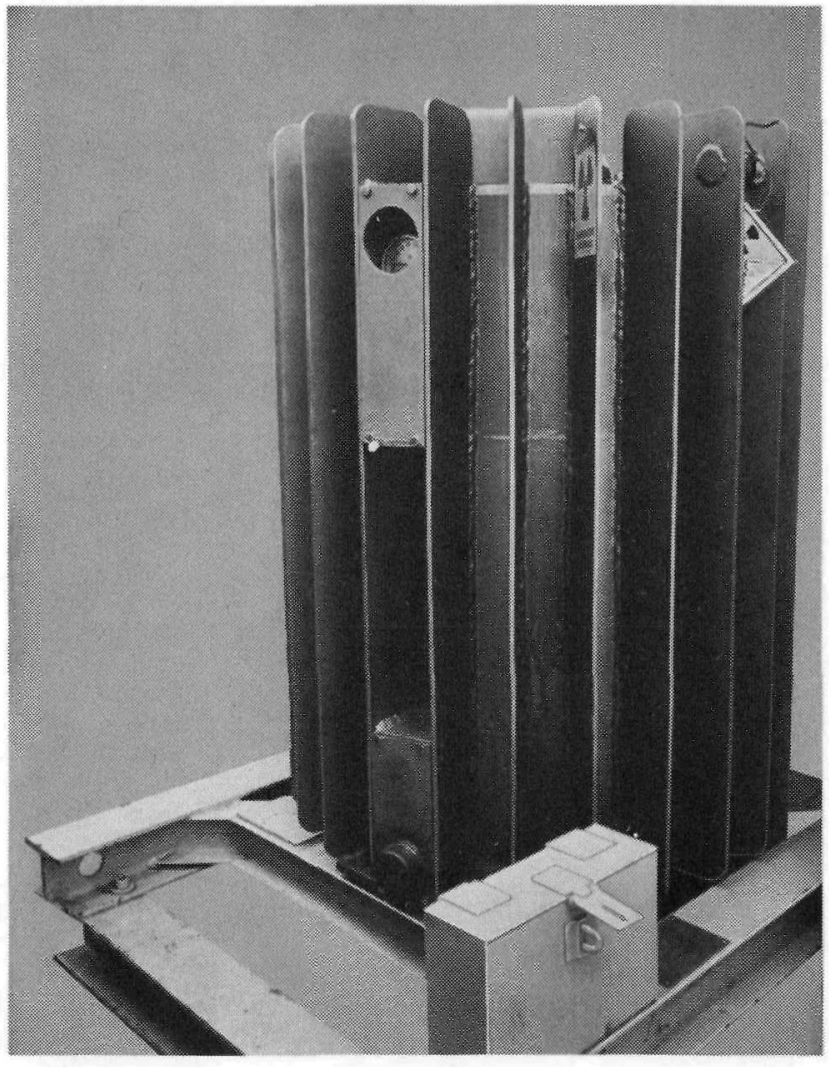

FIGURE 7 - Ground shipping cask (GSC) for SNAP-27 heat source. 
Table 1

DESIGN PARAMETERS FOR SNAP-27 HEAT SOURCE CAPSULE

Thermal Loading (W)

Fue1 Form

Fue1 Geometry

Fuel Specific Power $(\mathrm{W} / \mathrm{g})$

Physical Density Range of

Fue1 Particles $\left(\mathrm{g} / \mathrm{cm}^{3}\right)$

Fuel Effective Power Density $\left(\mathrm{W} / \mathrm{cm}^{3}\right)$

Fuel Effective Thermal Conductivity

$\left(\mathrm{Btu} / \mathrm{hr} / \mathrm{ft} /{ }^{\circ} \mathrm{F}\right)$ in $98 \%$ helium at

$1400^{\circ} \mathrm{F}$ clad temperature
$1480 \pm 30$

$238 \mathrm{PuO}_{2} \mathrm{Microspheres}$

50 to $250-\mu \mathrm{m}$ diam

Cylindrical Annulus

$0.400 \pm 0.01$

$9.1-10.3$

$2.6+0.2$

$-0.1$

0.62
Fueled Length (in.)

(cm)

Capsule o.d. (nominal, uncoated) (in.) (cm)

Clad Material

Emissive Coating

Emissivity

Mission Time (yr)

Storage Time (yr)

Total Capsule Weight (w/backplate) (1b) $(\mathrm{kg})$
13.76

$(34.95)$

2.509

$(6.373)$

Haynes alloy No. 25

Radifrax RC-356

0.85 (minimum)

1

2

15.46 maximum (7.03 maximum) 